
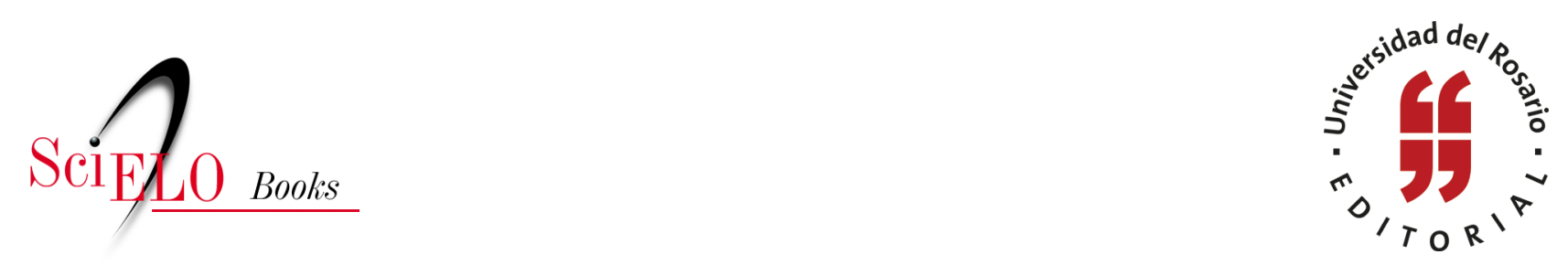

\title{
Pautas de atención penitenciaria a poblaciones excepcionales
}

\author{
Carol Iván Abaunza Forero \\ Mónica Alexandra Mendoza Molina \\ Paola Bustos Benítez \\ Giovanny Paredes Álvarez \\ Karla Vanessa Enriquez Wilches \\ Andrea Carolina Padilla Muñoz
}

\section{SciELO Books / SciELO Livros / SciELO Libros}

ABAUNZA FORERO, C.I., MENDOZA MOLINA, M.A., BUSTOS BENÍTEZ, P., PAREDES ÁlVAREZ, G., ENRIQUEZ WILCHES, K.V., and PADILHA MUÑOZ, A.C. Pautas de atención penitenciaria a poblaciones excepcionales. In: Adultos mayores privados de la libertad en Colombia [online]. Bogotá: Editorial Universidad del Rosario, Instituto Rosarista de Acción Social - SERES, 2014, pp. 56-59. ISBN 978-958-738-532-8. https://doi.org/10.7476/9789587385328.0006.

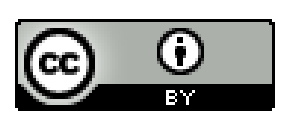

All the contents of this work, except where otherwise noted, is licensed under a Creative Commons Attribution 4.0 International license.

Todo o conteúdo deste trabalho, exceto quando houver ressalva, é publicado sob a licença Creative Commons Atribição $\underline{4.0}$.

Todo el contenido de esta obra, excepto donde se indique lo contrario, está bajo licencia de la licencia Creative Commons $\underline{\text { Reconocimento } 4.0 .}$. 


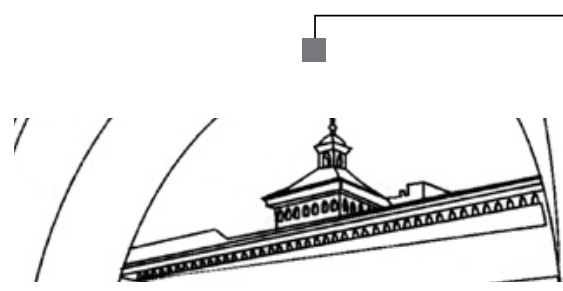




\section{Pautas de atención penitenciaria a poblaciones excepcionales}


El Inpec ha diseñado pautas de integración social dirigidas a grupos con condiciones excepcionales, que optan por la inclusión y la solución a necesidades culturales a través de la participación (tabla 1).

Tabla 1. Pautas de atención para poblaciones excepcionales

\begin{tabular}{|c|c|}
\hline $\begin{array}{l}\text { Población } \\
\text { excepcional }\end{array}$ & Pautas de atención \\
\hline Madres gestantes & $\begin{array}{l}\text { - Control prenatal. } \\
\text { - Culminación adecuada del embarazo, involucrando a la familia. } \\
\text { - Coordinación de programas pedagógicos con instituciones pú- } \\
\text { blicas y privadas. }\end{array}$ \\
\hline Madres lactantes & $\begin{array}{l}\text { - Control posparto. } \\
\text { - Control de crecimiento y desarrollo. } \\
\text { - Coordinar con el ICBF la atención integral de madres e hijos/hijas. } \\
\text { - Promover la lactancia materna. }\end{array}$ \\
\hline Indígenas & $\begin{array}{l}\text { - Certificar con la autoridad indígena competente la pertenencia } \\
\text { - Pel recluso a su comunidad. } \\
\text { de origen. } \\
\text { - Prevenir el desarraigo cultural, facilitando el contacto con la } \\
\text { familia y la comunidad. } \\
\text { - Coordinar la provisión de gastos de transporte al lugar de origen, } \\
\text { - en caso de otorgarse la libertad. } \\
\text { - Apoyar presupuestalmente las acciones adelantadas por las or- } \\
\text { - Apoyarion las actividades de asistencia y acompañamiento empren- } \\
\text { - didas por las autoridades indígenas. } \\
\text { - } \text { establecer convenios de cooperación entre el Inpec y entidades } \\
\text { - Ajustarse al marco de referencia que rige para pueblos indígenas. }\end{array}$ \\
\hline Afrocolombianos & $\begin{array}{l}\text { - Prevenir el desarraigo cultural, facilitando el contacto con la } \\
\text { familia y la comunidad. } \\
\text { - Apoyar las actividades de asistencia y acompañamiento empren- } \\
\text { didas por las comunidades negras. } \\
\text { - Establecer convenios de cooperación entre el Inpec y entidades } \\
\text { públicas y privadas para brindar apoyo a esta población. }\end{array}$ \\
\hline
\end{tabular}




\begin{tabular}{|l|l|}
\hline \multirow{4}{*}{ Adultos mayores } & $\begin{array}{l}\text { - Facilitar el acceso a los programas de promoción y prevención. } \\
\text { - Considerar factores de riesgo físico, psicológico o social, que impi- } \\
\text { dan el adecuado desenvolvimiento en las actividades cotidianas. } \\
\text { - Fomentar la colaboración de organismos nacionales e interna- } \\
\text { cionales que trabajen en pro de los AMPL. }\end{array}$ \\
\hline Extranjeros & $\begin{array}{l}\text { - Facilitar el contacto con las autoridades consulares de su país. } \\
\text { - Propender por hacer la inducción al establecimiento en el idioma } \\
\text { - Prevenir el desarraigo cultural, facilitando el contacto con auto- } \\
\text { ridades consulares y la familia. } \\
\text { - Fomentar la colaboración de organismos nacionales e interna- } \\
\text { cionales que trabajen en pro de los reclusos extranjeros. }\end{array}$ \\
\hline Personas con disca- & $\begin{array}{l}\text { Velar por que la ubicación física del interno responda a sus limi- } \\
\text { taciones y locomoción. }\end{array}$ \\
pacidad & $\begin{array}{l}\text { Considerar factores de riesgo o necesidad de acondicionamiento } \\
\text { Gestionar el suministro de ayudas técnicas o tecnológicas para } \\
\text { su desempeño autónomo. } \\
\text { Fomentar la colaboración de organismos nacionales e interna- } \\
\text { cionales que trabajen en pro de las personas con discapacidad en } \\
\text { reclusión. }\end{array}$ \\
\hline
\end{tabular}

Fuente: información tomada del Programa de Integración Social para Personas con Condiciones Excepcionales. Elaboración propia.

Este programa, sin embargo, no se consolida como una directriz estructurada de tratamiento diferencial ni establece parámetros claros para cada población; por el contrario, y muy posiblemente por la escasez de recursos con los que cuenta el Inpec, se limita a proponer una serie de acuerdos de cooperación con organismos externos, que puedan aportar a la integración de estas poblaciones, como parte de su objeto misional. De esta manera, es posible afirmar que en la actualidad el Inpec no cuenta con una política clara de tratamiento diferencial, aunque se reconoce la conciencia de la institución sobre esta problemática particular. 